HNO 2021 69 (Suppl 2):S99

https://doi.org/10.1007/s00106-021-01085-2

Online publiziert: 13. Juli 2021

(c) Der/die Autor(en) 2021

\section{Erratum zu: Bedürfnisse und Belastungen von palliativmedizinisch mitbetreuten Patienten mit fortgeschrittenen und/oder metastasierten Kopf-Hals- Tumoren}

\author{
C. Roch ${ }^{1}$ P. Schendzielorz ${ }^{2}$. A. Scherzad ${ }^{2}$ - B. van Oorschot ${ }^{1} \cdot$ M. Scheich ${ }^{2}$ \\ ${ }^{1}$ Interdisziplinäres Zentrum Palliativmedizin, Universitätsklinikum Würzburg, Würzburg, Deutschland \\ ${ }^{2}$ Klinik und Poliklinik für Hals-, Nasen- und Ohrenkrankheiten, plastische und ästhetische Operationen, \\ Universitätsklinikum Würzburg, Würzburg, Deutschland
}

\section{Erratum zu: \\ HNO 2020 \\ https://doi.org/10.1007/s00106-020- \\ 00888-z}

Der Artikel „Bedürfnisse und Belastungen von palliativmedizinisch mitbetreuten $\mathrm{Pa}$ tienten mit fortgeschrittenen und/oder metastasierten Kopf-Hals-Tumoren" von C. Roch, P. Schendzielorz, A. Scherzad, B.van Oorschot und M. Scheich wurde ursprünglich Online First ohne „Open Access" auf der Internetplattform des Verlags publiziert. Nach der Veröffentlichung in Band 68 Heft 7 pp. 510-516 hatten sich die Autoren für eine "Open Access"Veröffentlichung entschieden. Das Urheberrecht des Artikels wurde deshalb in (c) Der/die Autoren 2020 geändert.

Dieser Artikel ist jetzt unter der Creative Commons Namensnennung 4.0 International Lizenz veröffentlicht, welche die Nutzung, Vervielfältigung, Bearbeitung, Verbreitung und Wiedergabe in jeglichem Medium und Format erlaubt, sofern Sie den/die ursprünglichen Autor(en) und die Quelle ordnungsgemäß nennen, einen

Die Online-Version des Originalartikels ist unter https://doi.org/10.1007/s00106-020-00888-z zufinden.
Link zur Creative Commons Lizenz beifügen und angeben, ob Änderungen vorgenommen wurden. Die in diesem Artikel enthaltenen Bilder und sonstiges Drittmaterial unterliegen ebenfalls der genannten Creative Commons Lizenz, sofern sich aus der Abbildungslegende nichts anderes ergibt. Sofern das betreffende Material nicht unter der genannten Creative Commons Lizenz steht und die betreffende Handlung nicht nach gesetzlichen Vorschriften erlaubt ist, ist für die oben aufgeführten Weiterverwendungen des Materials die Einwilligung des jeweiligen Rechteinhabers einzuholen. Weitere Details zur Lizenz entnehmen Sie bitte der Lizenzinformation auf http://creativecommons. org/licenses/by/4.0/deed.de.

\section{Korrespondenzadresse}

\section{Dr. C. Roch}

Interdisziplinäres Zentrum Palliativmedizin, Universitätsklinikum Würzburg Josef-Schneider-Str. 11, 97080 Würzburg, Deutschland roch_c@ukw.de

Funding. Open Access funding enabled and organized by Projekt DEAL.
Open Access. Dieser Artikel wird unter der Creative Commons Namensnennung 4.0 International Lizenz veröffentlicht, welche die Nutzung, Vervielfältigung, Bearbeitung, Verbreitung und Wiedergabe in jeglichem Medium und Format erlaubt, sofern Sie den/die ursprünglichen Autor(en) und die Quelle ordnungsgemäß nennen, einen Link zur Creative Commons Lizenz beifügen und angeben, ob Änderungen vorgenommen wurden.

Die in diesem Artikel enthaltenen Bilder und sonstiges Drittmaterial unterliegen ebenfalls der genannten Creative Commons Lizenz, sofern sich aus der Abbildungslegende nichts anderes ergibt. Sofern das betreffende Material nicht unter der genannten Creative Commons Lizenz steht und die betreffende Handlung nicht nach gesetzlichen Vorschriften erlaubt ist, ist für die oben aufgeführten Weiterverwendungen des Materials die Einwilligung des jeweiligen Rechteinhabers einzuholen.

Weitere Details zur Lizenz entnehmen Sie bitte der Lizenzinformation auf http://creativecommons.org/ licenses/by/4.0/deed.de. 